\title{
Mural para um fotógrafo: um quadro e sua intenção
}

\section{Resumo}

O presente artigo propõe uma reflexão sobre a "qualidade intencional" do quadro Mural para um fotógrafo, de autoria de Franz Wilhelm Seiwert. Não se trata, entretanto, de um estudo sobre o fato narrado na obra em questão, mas sim da forma como seu autor o narrou segundo sua percepção do mundo inscrita na interpretação que ele faz do real circunstanciada por diversos fatos sociais.

Palavras-chave:

Progressistas de Colônia, Arte Exata, August Sander 


\section{Mural for a photographer: a picture and it's intention}

\section{Abstract}

This article proposes a reflection about the "intentional quality" of the picture Mural for a Photografer by Franz Wilhelm Seiwert. It isn't, however, the study about the fact related in the cited work, but really about the form how inscribed in the interpretation he makes about the "real" circumstantiated by several social facts. 
M ural para um fotógrafo, 1922 [figura 01], de autoria de Franz Wilhelm Seiwert (1894-1933), foi produzido para presentear o fotógrafo alemão August Sander (1876-1964) com o qual Seiwert e o grupo de artistas que freqüentava, os Progressistas de Colônia (Kölner Progressiven), mantiveram relações bastante estreitas. Relação esta que viabilizou a ascensão de Sander ao status de artista de vanguarda, e abriu as portas para sua inserção no meio artístico vanguardista. Desta proximidade Sander extrai concepções teóricas de ordem estética e política que pesaram na ressignificação dos retratos que produziu ao longo de sua carreira profissional, e na escolha de novos parâmetros técnicos e estéticos que embasaram a elaboração e estruturação de sua principal obra Homens do século XX (doravante HSXX).

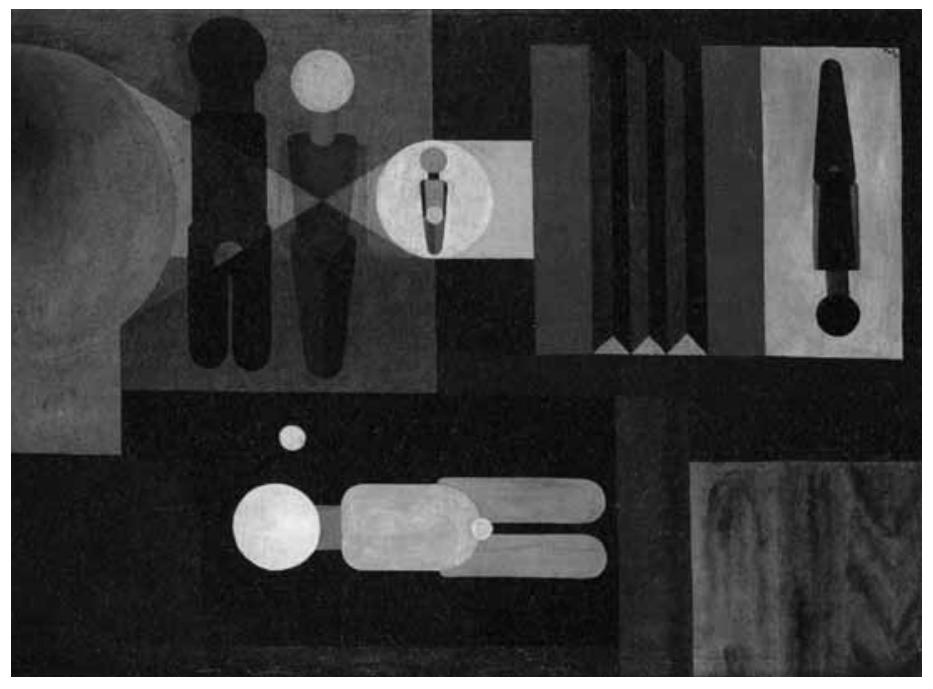

Figura 1

F. W. Seiwet, Mural para um fotógrafo, 1922, óleo sobre madeira, $110 \times 154,5 \mathrm{~cm}$ 
Mas não é sobre HSXX que nos deteremos. Tampouco se trata de um estudo sobre o fato narrado em Mural para um fotógrafo, o que nos interessa é sua "qualidade intencional" (BAXANDAL, 2006) na qual estão implícitas as relações deste objeto com as circunstâncias em que ele foi produzido. Interessa-nos também a forma como seu autor o narrou segundo sua percepção do mundo inscrita na interpretação que ele faz do real circunstanciada por diversos fatos sociais.

\section{Progressistas de Colônia: desmanchar o sólido e recriar o novo}

[...] toda forma deve ela mesma se destruir, para poder encontrar uma forma nova.

F.W. Seiwert

A arte é uma forma de interlocução entre o artista e a sociedade; é por meio dela que o artista se posiciona frente à realidade. Mas é no encontro de afinidades éticas e estéticas que artistas se aglutinam em grupos ou tendências, propõem novas necessidades estéticas, rompem com outras concepções artísticas do presente e do passado, e renovam ou substituem as velhas vanguardas. Foi assim com os expressionistas, que romperam com a estética romântica e com a estética impressionista; assim foi com a Nova Objetividade, que condenou o individualismo do Expressionismo; e assim foi com os Progressistas de Colônia, que se opuseram ao realismo da arte objetiva.

O grupo dos Progressistas de Colônia deve ser entendido num contexto artístico bem específico, a saber, o fim do Expressionismo e o retorno ao Realismo, com a Nova Objetividade de um lado e, de outro, o auge do Construtivismo na URSS e na Alemanha. Enquanto o Expressionismo proclamava a "espontaneidade criadora, a visão sempre subjetiva que deve ser dada através de uma obra, a preponderância do eu sobre a materialidade do real" (RICHARD, 1988, p.257), o Construtivismo de sua parte preconizava o fim da arte clássica burguesa em prol de uma arte funcional, racional e possível de ser mensurada, inspirada na materialidade técnico-científica.

Longe de serem dois grandes movimentos consensuais, Expressionismo e Construtivismo foram antes duas grandes tendências artísticas que reuniram, cada uma em seu interior, diversos grupos distintos e autônomos, onde inúmeros artistas e intelectuais encontraram espaço e força para se posicionarem frente à realidade, às formas de arte tradicionalmente 
estabelecidas e, em muitos casos, uns frente aos outros, motivados por princípios estéticos e políticos.

Nesse contexto de conflitos entre grupos, a objetividade antes negada pela arte com vocação mística do grupo Der blaue Reiter (O cavaleiro azul) ${ }^{1}$ é retomada pela Neue Sachlichkeit (Nova Objetividade). Surgida no lusco-fusco do Expressionismo alemão, quase como uma oposição ao Der Blau Reiter, pouco engajado com a problemática social acentuada pela desastrosa derrota da Alemanha na Primeira Guerra (ARGAN, 2006), a Nova Objetividade aspirava uma arte realista crítica pautada pela dura realidade social. As formas de representação iam da caricatura - como $O$ vendedor de fósforos I, 1920 [figura 02], de Otto Dix - ao figurativo estilizado - como Os pilares da sociedade, 1926 [figura 03], de George Grosz. Buscava-se a representação objetiva do mundo, possibilitando uma leitura clara de seu propósito de "apresentar uma imagem atrozmente verdadeira da sociedade alemã do pós-guerra" (ARGAN, 2006, p.242).

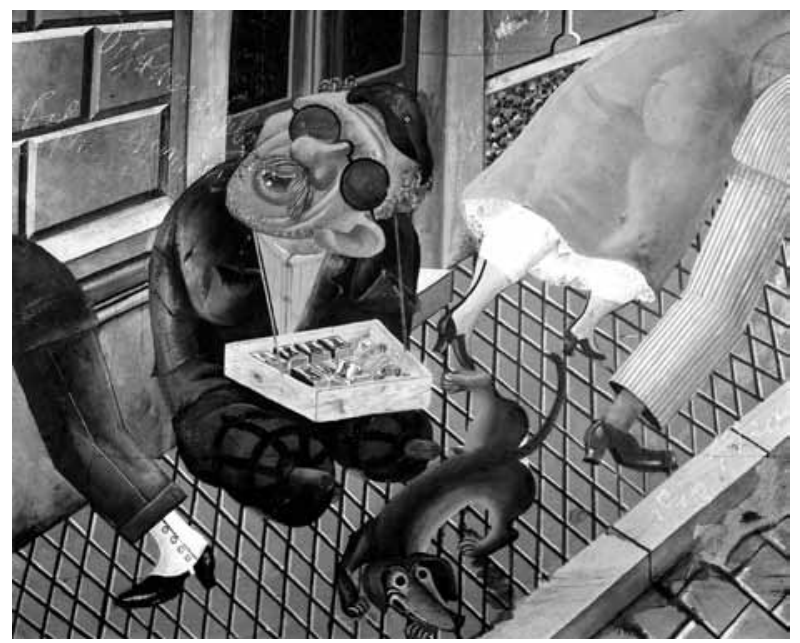

Figura 2: Otto Dix, O vendedor de fósforos I, 1920, óleo e colagem, 142x166cm

A Nova Objetividade foi um conjunto variado de tendências alinhado à esquerda política da República de Weimar. A temática da ala mais à esquerda caracterizava-se pela denúncia e pela ironia. George Grosz e Otto Dix, seus maiores expoentes, desenvolveram temas sobre a marginalização, a exploração social nas grandes cidades e os horrores da guerra. Freqüentemente empregavam figuras tipificadas, como vete-

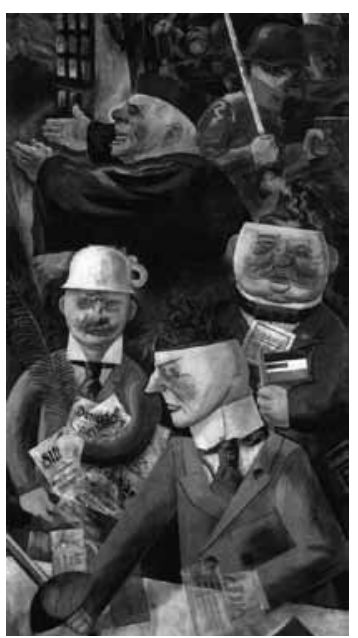

Figura 3

George Grosz, Os pilares da sociedade, 1926, óleo sobre tela, $200 \times 108 \mathrm{~cm}$. 
ranos de guerra, trabalhadores operários, miseráveis, boemia, classe dominante, militares, sacerdotes, prostitutas etc., bem como de ambientes representando, de um lado, a corrupção material e moral da poderosa classe dominante, e, de outro, a difícil condição social dos trabalhadores. Os assuntos tinham uma abordagem mordaz dos acontecimentos vividos e expunham claramente os antagonismos de classe, especialmente nos trabalhos de George Grosz, pintor que durante um tempo esteve filiado ao KPD (Partido Comunista Alemão), desde sua fundação em 1919.

A retomada do Realismo, tal como proclamava a Nova Objetividade, foi contraposta pela arte dos Progressistas de Colônia tanto no plano estético como no político. No plano estético, o realismo da arte dos artistas progressistas se desvencilhava da representação naturalista das formas dos objetos para dar vazão a uma representação figurativa de inspiração construtivista, imprimindo um estilo gráfico pautado pelo anonimato dos personagens representados, como também do artista: todo e qualquer indício que remetesse a uma expressividade subjetiva deveria ser eliminado. Identificados com princípios anarquistas de uma sociedade independente de instituições estatais, e com um projeto político e econômico construído por iniciativa do proletariado e não por um partido, suas artes acabaram por se tornar a extensão de suas atividades políticas, buscando romper com a exclusividade da arte capitalista, e desenvolvendo novas formas a fim de facilitar a comunicação de suas ideias aos trabalhadores a quem elas foram dirigidas (EVERETT, 1990).

No início dos anos 20, após um congresso de artistas progressistas realizado em 1922 na cidade de Dusseldorf, Franz Wilhelm Seiwert e Heinrich Hoerle fundam o grupo dos Progressistas de Colônia, ao qual se juntariam Gerd Arntz, Peter Alma, Otto Freundlich, dentre muitos outros. Próximos ao grupo estiveram Otto Coenen, Gottfried Brockmann, Anton Räderscheidt, os dadaístas Max Ernst e Theodor Baargeld, e o fotógrafo August Sander.

O grupo se constitui em meio a um ambiente artístico e intelectual efervescente na cidade de Colônia. No plano intelectual, a cidade contava com a Universidade Urbana de Colônia, fundada por Leopold Wiese em 1919, concomitantemente ao surgimento de outras importantes universidades, como a Escola de Frankfurt. Segundo Ringer, a chamada Escola de Colônia representou "uma das tradições mais importantes e produtivas da sociologia alemã moderna” (2000, 
p.216). No plano da arte, "o clima artístico de Colônia dos anos 20 resultava claramente da influência dos Progressistas de Colônia (LANGE; HEITING, 1999, p.172), e também do atuante "Grupo D" (dadaístas), em constante contato com o grupo Dada de Berlim.

A literatura a respeito dos Progressistas de Colônia à qual tive acesso não apresenta nenhuma clara definição do grupo enquanto tal. A meu ver, ele se caracterizava como uma associação de artistas relativamente aberta, embora a funcionalidade social da arte fosse um pressuposto. Sequer havia um manifesto que traçasse suas diretrizes; ao contrário, estas eram expressas por seus membros como opiniões nos diversos artigos publicados na revista a bis z - único elemento que caracterizava certa organização formal do grupo. Tal revista, por sinal, foi bastante plural na medida de sua orientação ideológica; além de Sander e das obras e artigos publicados por seus membros em todas as edições, a revista contou com a participação de muitos artistas da vanguarda alemã e internacional, como o dadaísta Raoul Hausmann; Lázsló Moholy-Nagy, da Bauhaus; o holandês Peter Alma, que viria aderir ao grupo; e Augustin Tschinkel, de Praga, dentre outros. Nela foram publicados extratos de artigos escritos por Bakunin, resenhas de livros feitas pelo intelectual e militante anarquista Alexander Berkman, e artigos sobre a teoria do comunismo (EVERETT, 1990).

Em seu curto período de existência (1929-1933), a bis z conseguiu um alcance bastante significativo. No âmbito geográfico, sua distribuição contabilizava contatos na Alemanha, Âustria, Suíça, Polônia, URSS, Turquia, Holanda, Bélgica, França, EUA, México, Índia e Palestina (EVERETT, 1990). A repercussão nacional e internacional de a bis z foi responsável pela projeção do grupo e, de certa forma, de August Sander, que além de publicar as reproduções fotográficas dos quadros dos progressistas - como veremos mais adiante -, também publicou várias fotografias de Antlitz der zeit (Rostos de uma época), nome da primeira publicação de HSXX em 1929.

Apesar de ter contado com a participação de Hoerle na fundação do grupo, Franz Wilhelm Seiwert consolidou-se como uma espécie de líder natural e intelectual do grupo. Tendo iniciado sua vida de artista numa chave expressionista (ROTH, 2008), Seiwert mudaria radicalmente a orientação de sua arte após entrar em contato com os escritos de Karl Marx e Rosa Luxemburgo. A partir de então, ele procurou conciliar sua prática artística com sua consciência política. Seu enga- 
jamento o aproximou de artistas filiados à esquerda política, como Max Ernest e Johannes Theodor Baargeld, ambos do Grupo D, além de Heinrich Hoerle. Em 1919, Seiwert e Hoerle rompem com os dadaístas logo após a seção de arte dadaísta cujo catálogo publicou algumas de suas obras (ROTH, 2008).

O peso intelectual de Seiwert para o grupo dos Progressistas de Colônia fica patente no fragmento de uma carta dirigida ao escritor luxemburguês Pols Michels (1897-1956) em 1919, onde ele enuncia um dos fundamentos que norteariam a arte do grupo Stupid, primeira versão dos Progressistas de Colônia:

Porque nós somos apenas pintores e escultores, nós começaremos a partir de nós mesmos. Tentaremos ser tão simples, tão diretos dentro das formas dadas da pintura e da escultura de modo que todos poderão nos entender. [...] Nós sabemos que não há realidade que possa ser confundida com a realidade da pintura e da escultura. Nós queremos tornar a realidade da pintura e da escultura tão diretamente real que ninguém poderá confundi-la com outra realidade qualquer (apud ROTH, 2008, p.48; tradução nossa).

"Começaremos a partir de nós mesmos" significou dizer que uma mudança radical na arte deveria acontecer primeiramente nos pintores e escultores, para depois reformular a forma, tornando-a simples e clara. A arte não poderia ser percebida como a realidade em si, mas como a realidade artística propriamente dita. No inicio dos anos 30, Seiwert dirá que reportar a realidade tal qual ela é, é encargo da fotografia, como veremos mais adiante.

Seiwert, num artigo publicado em 1930 na revista $a$ bis $z$, dizia que o "trabalho individual de arte como confirmação de um tipo egocêntrico de pessoa, por um lado, e, por outro, nas mãos de seu proprietário, confirmando sua designação de possuidor" (apud EVERETT, 1990, p.03), é algo inconcebível, mas compatível com o espírito capitalista que individualiza a arte, separando-a da sociedade - como se a arte não resultasse da sociedade, mas apenas da vontade e da pulsão individual -, e a transforma em produto. Porém, criar uma arte nova dentro de um modelo capitalista tornava-se tarefa utópica, pois qualquer coisa verdadeiramente nova na arte teria primeiro que ser criada fora dela, dentro da e pela classe trabalhadora livre da subordinação cultural burguesa (MATTICK JR., 1988), ou 
mesmo comunista, como ele próprio não perdeu a oportunidade de criticar em muitos de seus escritos.

Para Seiwert, não enxergar essa condição da arte recai no equívoco dos artistas comunistas que acreditavam estar de fato fazendo uma arte proletária. A seus olhos, abordar claramente conteúdos que denunciem a corrupção material e moral da poderosa classe dominante, a difícil condição social dos trabalhadores (temas centrais das obras de George Grosz), ou mesmo mostrar a mobilização do proletariado em torno de uma causa partidária - como no quadro O bolchevique, 1920, do artista soviético Boris Kustodiev -, não é suficiente para tornar a arte proletária. Ao contrário, para ele, essas obras não levam o proletariado a se libertar de sua condição de subordinado à ordem cultural e política estabelecida; a luta de classes está sendo posta em nome de uma causa partidária e não do proletariado em si, e, nesse sentido, a cultura comunista não difere da capitalista, pois o homem continua preso a uma cultura de obediência e de reprodução da ordem.

Só porque o seu conteúdo tem uma tendência a ser "proletário", fazendo declarações sobre a luta, a solidariedade e a consciência de classe do proletariado, a arte burguesa não se tornou ainda arte proletária. As formas devem ser subservientes ao conteúdo: o conteúdo deve reformular a forma e torná-la conteúdo. O trabalho para que isto aconteça é criado a partir da consciência coletiva em que o self, que cria um trabalho, já não é burguês individualista e isolado, mas fruto da consciência coletiva (apud EVERETT, 1990, p.8-9).

Não obstante, dentro desse contexto, uma nova forma artística poderia ser posta, com o intuito não de apenas despertar a classe trabalhadora para a luta de classes, mas para despertar sua consciência em relação à sua condição dentro de qualquer sistema social. Seria preciso, então, reformular a forma, desmanchando a forma consolidada da arte capitalista burguesa individual, subjetiva e comercial, e trazer à tona o objetivo, o universal e o racional, com o intuito de escancarar a cultura à qual as estruturas sociais se conformam, a partir de uma linguagem compreensível por todos. Também seria preciso superar as formas naturalistas caricaturais e estilizadas re-apropriadas pela Nova Objetividade para criar "uma arte mais anônima [...] e de inspiração mais coletiva” (LUGON, 2001, p.70). 


\section{Mural para um fotógrafo: o sentido do trabalho}

Para o artista progressista Otto Freundlich,

A arte sistemática que nós queremos produzir oferece a cada um a possibilidade de escapar dos pensamentos e das imagens com conteúdos do passado, e oferece, ao mesmo tempo, a possibilidade de uma independência absoluta. Nós eliminamos, portanto, de nossa concepção pictorial a representação de pessoas, de coisas, a perspectiva da Renascença e a ilusão plástica [...] (FREUNDLICH apud MATTICK JR., 1988, p.2, tradução nossa).

Mural para um fotógrafo, quadro com que Franz Wilhelm Seiwert presenteou August Sander, é um bom exemplo da arte progressista segundo a definição proposta por Freundlich. Esse quadro trata da representação do trabalho de um fotógrafo dentro de seu estúdio durante uma seção de retratos. Seus elementos internos - personagens e objetos - são construídos basicamente por formas geométricas bastante simples: quadrados, retângulos, triângulos e círculos.

A estrutura da obra é igualmente geometrizada. O espaço da tela é organizado basicamente em retângulos e quadrados, os quais têm por função organizar a representação espacial do estúdio em si: cada retângulo e cada quadrado representa uma área do estúdio diferenciada por um jogo de luz e sombra que varia conforme o grau de saturação e brilho das cores que melhor se adéquam à representação de cada ambiente. Por exemplo, o quadrado onde se encontram os dois modelos um homem (esquerda) e uma mulher (direita) - representa o cenário da seção fotográfica; sua iluminação é suave e de pouco contraste, e o amarelo e o laranja não vibram tanto quanto vibram as cores homólogas impressas na objetiva da câmera e na cabeça do fotógrafo (círculo grande e laranja à esquerda).

O corpo da câmera e sua base de sustentação estruturam o lado direito do quadro onde ocorre o efeito da cena representada, a saber, a concretização do ato fotográfico. Do outro lado, estão o cenário e o fotógrafo, localizados junto à margem esquerda da obra. Os elementos visuais que evidenciam o personagem são seu tamanho e a mancha escura na parte superior esquerda da cabeça, que representa uma sombra. $\mathrm{O}$ detalhe da sombra evidencia o ponto de vista quase frontal do fotógrafo em relação aos modelos; o tamanho avantajado estabelece seu posicionamento no primeiro plano da cena, bem 
como a relação de proporção e de distância espacial entre ele e os personagens ao fundo.

A composição da imagem se constitui num bonito jogo de formas, cores e contrastes articulados na construção tridimensional do objeto, a qual se dá por meio da justaposição de planos fora de uma ordem lógica de visualização conforme a representação tradicional da perspectiva da pintura acadêmica. Por exemplo, o retângulo horizontal na parte inferior do quadro, onde está pintada a figura do personagem masculino sobre um fundo preto, representa a imagem negativa traduzida em valores de branco, cinza e preto. Ele também ilustra o visor da câmera que está à frente do fotógrafo - seu ombro está sobreposto ao retângulo. A ilustração da máquina fotográfica mostra seu interior; ela está representada por um corte lateral, como geralmente se faz nos desenhos técnicos, e por isso vemos a figura feminina apenas na lente e no fundo da câmera onde a imagem está se formando invertida, de ponta-cabeça e em preto e branco.

Assim, a justaposição de planos funciona como um sistema que permite ora a análise minuciosa de cada parte da obra - ou do sistema -, ora uma análise do conjunto. Esse sistematismo revela a raiz construtivista da obra, que pode ser estendida para as obras dos outros membros dos Progressistas de Colônia. Toda a concepção estrutural do quadro é técnica, possível de ser calculada matematicamente; as formas são claras e algumas tão precisas a ponto de terem sido feitas com auxílio de alguma ferramenta, como um compasso, um gabarito, ou mesmo réguas os triângulos que representam os ângulos de visão do fotógrafo e da câmera mesclam a precisão da régua e a do compasso. A compreensão da imagem exige uma leitura igualmente sistemática, que faz com que seus elementos sejam lidos com muita objetividade e clareza. Mural para um fotógrafo é um quadro de fácil compreensão em si; a simplicidade de sua estrutura formal e das figuras estampadas propicia uma leitura descritiva - não imediata ${ }^{3}$, mas minuciosa - das partes e do todo.

O que está posto em jogo nesse quadro é a intenção (BAXANDALL, 2006) realista da obra. No plano estético, a arte dos Progressistas de Colônia se desvencilha das formas naturalistas do Realismo Socialista e da representação caricata de George Grosz e Otto Dix, dando espaço a um figurativismo estilizado onde a cor e a forma conformam objetos reconhecíveis, sem, entretanto, apelar à representação naturalista. Não se tratava da forma pela forma, mas da forma submetida a um conteúdo que atuasse no sentido de libertar o trabalhador da cultura de exploração que o aliena de sua verdadeira condição. 
No quadro Mural para um fotógrafo, o plano político está subjacente à obra, e a abordagem objetiva do real está posta claramente, o que deve ser entendido dentro do conceito de arte exata que norteou os trabalhos dos Progressistas de Colônia. No âmbito da estética, a exatidão se caracteriza por sua capacidade descritiva possibilitada pela construção sistemática, pela estrutura geométrica e pela geometria das figuras humanas, simplificadas e construídas quase como pictogramas. No plano do conceito, a estrutura formal não apenas deve possibilitar a fácil identificação dos espaços e dos personagens representados, como também deve estar submetida ao conteúdo. No plano político, está posto o sentido do trabalho e não a exploração do trabalho: Mural para um fotógrafo representa mais do que um ambiente de trabalho e uma profissão; em sua forma, está inscrito o que dá sentido ao trabalho do fotógrafo. Por exemplo, a cabeça do fotógrafo, a lente e o corpo da objetiva, o interior da câmera e o personagem pintado no retângulo horizontal na parte inferior do quadro, são as partes mais iluminadas da cena. E isso não é um acaso. Trata-se da representação do ato de observação; do ponto de vista do fotógrafo sobre o sujeito/ realidade - os ângulos de visão do fotógrafo e da câmera são mostrados em forma de um triângulo que converge em cima do personagem do centro -; da objetividade da fotografia, capaz de captar uma imagem fiel e mecanicamente; e da reprodutibilidade graças à imagem em negativo.

\section{Da reprodutibilidade}

Para que o que está sendo proposto faça sentido, é preciso lembrar que Mural para um fotógrafo foi um presente de Seiwert para Sander, e o sentido desse presente deve ser entendido na gênese da ligação de August Sander com os Progressistas de Colônia.

O início de tal relação - entre 1920 e 1921 - foi intermediado por um cliente de Sander, o violoncelista Willi Lamping, que o apresentou a Franz Wilhelm Seiwert (MARESCA, 1996). Sem ter como comprovar, minhas leituras me levam a deduzir que não foi o interesse pela produção fotográfica de Sander que os aproximou de imediato - mesmo porque a produção fotográfica este último ainda era essencialmente comercial -, mas sim a necessidade de uma prestação de serviços fotográficos por alguém tecnicamente competente: reproduzir fotograficamente os quadros dos Progressistas de Colônia. 
O que está por trás dessa prestação de serviços é o caráter técnico reprodutível da fotografia que atenderia duas preocupações dos artistas de Colônia: 1) a documentação da obra para a posteridade ${ }^{4}$; e 2) a reprodução das obras pelas técnicas de artes gráficas, possibilitando a impressão de suas pinturas em jornais e revistas da esquerda política, como o jornal Die Aktion, editado pelo anarquista Franz Pfemfert, o Die Proletarische Revolution, o Sozialistische Republik e a revista a bis z. Para os artistas progressistas, a reprodutibilidade já era uma realidade, e parte significativa de sua produção artística eram impressões a partir da técnica da xilogravura e da litogravura. A respeito disso, há uma hipótese a ser considerada. Segundo Giulio Carlo Argan,

a técnica da xilogravura [primeiro meio técnico de reprodução de imagens] é arcaica, artesanal, popular, profundamente arraigada na tradição ilustrativa alemã. Mais do que uma técnica no sentido moderno da palavra, é um modo habitual de expressar e comunicar por meio da imagem (2006, p.238).

Embora eu não tenha como aprofundar essa reflexão, pois necessitaria encontrar pistas na história da arte alemã, como também na trajetória de vida de alguns dos principais personagens do grupo, parece-me válido pensar na hipótese de que a tradição de comunicação e expressão por meio da xilogravura na arte alemã possa de fato ser a raiz da opção dos Progressitas de Colônia, e de outros artistas contemporâneos a eles, pelo emprego de diferentes técnicas de gravura. Entretanto, é possível pensar numa outra hipótese: a de que a tradição ilustrativa da arte alemã da qual fala Argan está arraigada numa cultura social da imagem que ficaria ainda mais exacerbada no entre-guerras. Nesse período, as diversas formas de artes gráficas (de processos manuais como a xilogravura e a litogravura, à tipografia e à fotomecânica) e a difusão de imagens estão em plena e rápida ascensão; “a reprodução das imagens experimentou tal aceleração que começou a situar-se no mesmo nível que a palavra oral" (BENJAMIN, 1994, p.167). Se imagem e palavra oral estão situadas no mesmo patamar, esse crescimento acelerado deve ser entendido num ambiente social favorável à profusão de imagens possível apenas numa sociedade aberta à imagem como interlocutora da realidade.

Nesse sentido, a reprodução fotográfica das obras dos Progressistas de Colônia pode ser entendida no curso do "entusiasmo e fé coletiva” (BASTIDE, 1979, p.12) em relação à fo- 
tografia no período de Weimar, seguindo, porém, orientação de ordem estritamente político-partidária. Sobre o entusiasmo e a fé na fotografia, Franz Roh dizia que:

Três fatores devem convergir logo que um dispositivo técnico permite ampliar neste ponto a história dos homens: o acesso a este dispositivo deve ser relativamente barato, seu uso deve ser tecnicamente fácil, e a tendência espiritual da época deve estar orientada na direção dos mesmos prazeres [visuais] (apud HAUS; FRIZOT, 1995, p.459; tradução nossa).

A "tendência espiritual da época" diz respeito ao fato de a fotografia responder a certa necessidade social. No período de Weimar, a fotografia - e também, mas de outra forma, o cinema - era o meio técnico mais acessível e de maior inserção social, graças ao seu desenvolvimento quantitativo (jornais diários, ilustrados, livros, revistas, publicidade), ao acesso ao aparato técnico simplificado e aos serviços fotográficos, e ao fato de ser uma linguagem típica do mundo moderno contemporâneo. Esse espírito de época foi percebido tanto pela vanguarda da fotografia e pela vanguarda artística, como pelo KPD (Partido Comunista Alemão), que em 1920 "declarou que a arte era uma 'arma' na luta de classes e encorajava os artistas do partido a abandonarem a pintura pela arte impressa" (ROTH, 2008, p.24-25). Para os comunistas, a fotografia deveria ser valorizada por seu potencial propagandístico (ROTH, 2008), por sua capacidade de penetração social devido a sua popularização. Mesmo estando em oposição aos comunistas alemães, os Progressistas de Colônia, alinhados a ideais anarquistas, compreenderam a relevância dessa orientação, e por isso assumiram a fotografia como meio de ampliar o alcance de suas obras, transbordando a fronteira geográfica:

A disseminação da pintura através de documentos fotográficos ultrapassou o campo das publicações. Na Exhibition of Western Revolutionary Art, em Moscou 1926, as reproduções fotográficas de Sander dos trabalhos de Seiwert, Hoerle e Antz entre outros, substituíram as próprias pinturas. Com a ajuda da fotografia, a pintura também poderia alcançar uma audiência diversa e internacional (ROTH, 2008, p.29).

O uso da imagem xilográfica e litográfica - apesar do avanço significativo da fotografia e pela reprodução mecânica das artes gráficas - não ficou para trás. Durante o processo revo- 
lucionário de 1918, muitos artistas engajados na vida política produziram xilogravuras manifestando suas posições políticas face aos acontecimentos da época. Algumas dessas obras foram inclusive reproduzidas em cartazes, como a xilogravura Memorial para Karl Liebknecht, de Käthe Kollwitz, na qual o povo aparece numa câmera mortuária chorando sobre o corpo estendido do líder revolucionário, violentamente assassinado junto com Rosa Luxemburgo pelos Freikorps 5 .

Dentre os Progressistas de Colônia, Franz Wilhelm Seiwert, de modo semelhante a Kollwitz, imprimiu em panfletos o retrato feito em xilogravura do socialista-anarquista Gustav Landauer, assassinado por reacionários durante a Revolução de 1918 (EVERETT, 1990). Outro artista progressista, Gerd Arntz, desenvolveu uma série litográfica para o portfólio Doze casas de uma época (1927); tratava-se uma representação em forma de pictogramas da estrutura social alemã através de doze tipos de estabelecimentos da era capitalista, como podemos ver nos exemplos Imóvel de habitação e Usina [figura 04]. O alcance de Arntz foi ainda maior: em 1930, ele é contratado pelo Museu Social e Econômico de Viena, sob a direção do economista Otto Neuraht, para criar um alfabeto visual em forma de pictogramas $^{6}$ que ilustraria painéis estatísticos sobre os fenômenos econômicos e sociais mundiais (LUGON, 2001). Muitos desses painéis serviram ao Método vienense de estatística ilustrada nas escolas, criado por Neurath, e foram publicados na revista dos Progressistas de Colônia a bis z, de 1932 (LUGON, 2001).
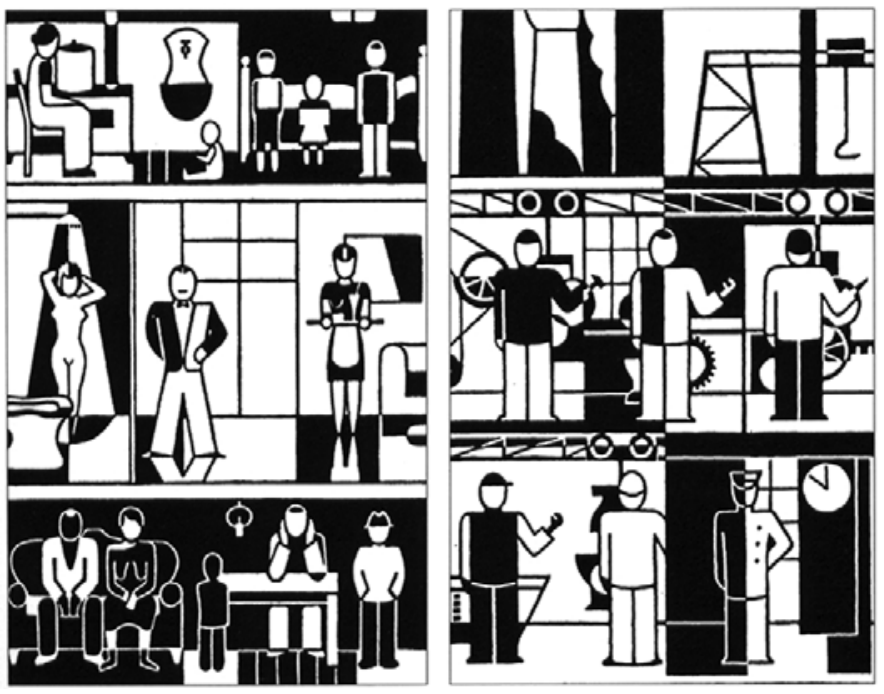

Figura 4

Gerd Arntz, Imóvel de habitação e Usina, da série Doze casas de uma época, 1927, litografia 
Concretamente, a difusão dessas obras estava fundamentada na atividade política, e o alcance de suas imagens atingia especialmente a militância da esquerda - elas eram publicadas em revistas e jornais ligados a grupos bem específicos. $\mathrm{O}$ alcance mais abrangente da população se dava por meio das xilogravuras e litografias reproduzidas em cartazes e panfletos, mas seguiam igualmente a motivação política. Para os Progressistas de Colônia, o papel social da arte não poderia ser outro senão o da participação ativa e transformadora da vida social.

\section{Da objetividade: nitidez, luminosidade e exatidão}

No bojo das reflexões que fomentavam a fotografia moderna alemã, a objetividade fotográfica estava na pauta do dia. Entendia-se por objetividade a precisão do detalhe que a fotografia direta - captada por uma câmera fotográfica e sem manipulações técnicas posteriores que alterem a imagem - proporcionava. A isso se relacionava a abordagem realista do mundo. A fotografia, por sua natureza técnica, era o meio capaz de reproduzir os objetos tal qual eles são: a precisão de detalhes, possibilitada pelas características técnicas do meio e pela habilidade do fotógrafo, restitui ao objeto fotografado um realismo absoluto ${ }^{7}$, como nenhuma outra forma de arte salvo o cinema - conseguia fazê-lo.

O historiador da arte Wolfgang Born ${ }^{8}$ afirmou que "o novo realismo que encontra sua satisfação na hiper-precisão do detalhe é a expressão de uma mentalidade atual racional" (apud LUGON, 1997, p.57) típica de uma geração de engenheiros, o que não implicava obrigatoriamente que a busca pela hiperprecisão fosse anestética e banal. Ao contrário, a hiper-precisão seria o caminho para fazer emergir "o sentido escondido atrás das coisas” (LUGON, 1997, p.57).

Nessa concepção, está posta a ideia da racionalidade fotográfica ${ }^{9}$, em que à natureza do aparato técnico é atribuída a capacidade fria e objetiva de captação da imagem, e ao fotógrafo, a capacidade consciente de representar a realidade. A busca pela hiper-precisão do detalhe resulta da ação consciente do fotógrafo. Na mesma linha de pensamento, numa reflexão sobre a fotografia científica, Hugo Sieker propôs que:

O aparelho fotográfico que é desprovido de consciência tem um olhar mais natural que o olho que está preso à consciência, pois que ele não pode fazer outra coisa que ver. Ele é um 
órgão da visão em si. Muito longe de ser assim perfeito como o olho humano, ele dispõe, entretanto, desta maravilhosa capacidade que consiste em ver com uma grande exatidão (na velocidade da luz) (apud LUGON, 1997, p.169).

Ver com exatidão foi meta de muitos fotógrafos desse período na Alemanha e alhures. Reconhecer a objetividade do aparato fotográfico desprovido de consciência como característica intrínseca do meio, significou ampliar novas possibilidades estéticas e o caminho para restituir o realismo ao objeto fotografado. Se, no século XIX, a objetividade do aparato fotográfico fora percebida como estando a serviço do registro científico, no período do entre-guerras a objetividade e a hiper-precisão de detalhes passaram também a ser percebidas por boa parte - não se tratava de um consenso absoluto - da vanguarda dos fotógrafos, artistas e críticos de arte como as qualidades da fotografia que melhor representariam o espírito da época.

Para os Progressistas de Colônia, objetividade e precisão de detalhes correspondiam ao ideal de arte exata; a mecanicidade da fotografia garantia a objetividade e a precisão na reprodução detalhada das obras, as quais eles "valorizavam repetidamente, [...] inclusive encorajando-o a capturar a 'plástica' ou a qualidade tátil de suas pinturas" (ROTH, 2008, p.30). Um dos primeiros indícios de interferência dos Progressistas de Colônia sobre a reorientação da fotografia de August Sander reside precisamente nesse ponto. Em 1922, Seiwert, impressionado com a qualidade do retrato de um camponês ocasionalmente copiado em papel fotográfico brilhante, motivou seu colega a buscar a nitidez absoluta dos retratos naquele tipo de material (LUGON, 2001).

O papel brilhante era produzido industrialmente, e até então estava restrito ao uso comercial e ao trabalho de documentação, em razão de uma suposta falta de beleza estética necessária aos trabalhos artísticos ou mesmo aos retratos comerciais. Tecnicamente, graças ao maior poder de reflectância, o brilho do papel favorece a reprodução de detalhes - como a textura -, realça as diferenças tonais, e aporta mais luminosidade às áreas claras da imagem. Esteticamente, a ideia de nitidez absoluta da qual fala Seiwert é referente ao aspecto realístico próprio da fotografia que o papel brilhante acentua por meio de sua capacidade de reproduzir detalhes com maior precisão.

A capacidade de reprodução de detalhes está relacionada a outros quesitos técnicos que extrapolam o tipo de papel fotográfico: tipo e tamanho de filme empregado, forma de 
processamento fotoquímico, e qualidade óptica das objetivas das câmeras. O próprio August Sander, numa carta (1925) destinada ao professor de história da arte Erich Stenger (18781957), um dos pioneiros a pesquisar a história da fotografia, explica suas escolhas técnicas:

Eu me utilizo, para obter uma fotografia clara e pura, de objetivas Zeiss, de uma placa [negativo de vidro] hortocromática munida de um filtro de luz adequado, e de um papel brilhante e claro que rende um excelente resultado nos detalhes. Eu amplio no tamanho de $18 \times 24 \mathrm{~cm}$ as fotos feitas com placas de $12 \times 16^{1 / 2} \mathrm{~cm}$ ou $13 \times 18 \mathrm{~cm}$ (SANDER apud LANGE; HEITING, 1999, p.172).

Ao adotar o papel brilhante, Sander se torna um dos precursores do uso desse tipo de papel no trabalho pessoal. Essa mudança técnica é mais do que um simples detalhe; ela é parte constituinte da fotografia exata que Sander lograva alcançar (ROSSI, 2010), é parte da reorientação formal de sua fotografia. Nitidez absoluta e luminosidade são dois termos técnicos que Sander adotou como fundamento estético daquilo que ele denomina fotografia pura e clara, aspectos estes que estão na raiz do conceito de fotografia exata.

Nitidez e luminosidade eram metas também de outros fotógrafos, especialmente os da Nova Objetividade, com destaque para seu maior representante, Albert Renger-Patzsch. Embora Renger-Patzsch e August Sander dessem igual valor a esses dois aspectos e à precisão de detalhes, objetividade e exatidão diferiam entre eles no plano conceitual e na prática fotográfica.

Para ambos, a luminosidade das cenas era um meio de enfatizar a objetividade e a exatidão dos objetos: o que se buscava era a clareza (compreensão) das fotografias. Luminosidade é um conceito técnico que diz respeito à maior abertura do diafragma que uma objetiva possui. Diafragma é o instrumento da objetiva que controla a quantidade de luz que será transmitida ao filme (ou, nos dias de hoje, ao sensor digital). A luminosidade é, portanto, uma característica que varia em cada objetiva e que depende da sua engenharia e do material óptico com o qual são feitos os seus componentes internos (lentes). Essa característica foi mobilizada pelo próprio Sander como forma de se alcançar a fotografia pura e clara. Entretanto, a ideia de luminosidade estava relacionada ao ato de fotografar e à forma como se copiavam as imagens (no caso de Sander, o uso do papel brilhante). Quanto 
ao ato fotográfico, a preocupação era evidenciar cada detalhe do objeto pelo controle absoluto da iluminação, de forma tal que as partes escuras devessem ser trabalhadas no sentido de evidenciar o objeto e de alcançar o máximo de detalhes que elas possam informar. "Em fotografia, não existem sombras que não se possam clarear", assim disse Sander (apud SANDER, G, 1995: capa).

A nitidez estava vinculada ao equipamento fotográfico: objetiva luminosa e de boa qualidade óptica, associada à câmera de grande formato que empregava negativos grandes, proporcionaria fotos com maior fidelidade e riqueza de detalhes. Na verdade, nitidez e luminosidade são aspectos indissociáveis, uma vez que essa dupla dá magnitude às texturas e aos detalhes dos objetos, proporcionando maior precisão às imagens.

\section{Do ponto de vista}

Em Mural para um fotógrafo, o personagem protagonista é mostrado não como um simples operador, mas como alguém que porta um ponto de vista sobre a realidade. O fotógrafo aparece no primeiro plano, e a cena é construída a partir do seu ponto de vista; ele é o agente principal. $O$ ângulo de visão está bem evidente e não há variação: fotógrafo e modelos estão posicionados numa relação de paridade muito parecida com a forma com que Sander constrói a maioria de seus retratos. É provável que Seiwert tenha feito uma alusão às fotografias de seu amigo ou, ainda, à nitidez absoluta e à clareza de informação de seus retratos - vale lembrar que o quadro data de 1922, mesmo ano em que Seiwert viu o retrato do camponês copiado em papel brilhante.

Sander não apelava para os ângulos inusitados. A câmera era geralmente posicionada na mesma altura do retratado, e os enquadramentos preservavam, em grande medida, a frontalidade. O que os diferia era a contextualização: enquanto os primeiros isolavam o objeto, Sander, na maioria das vezes, os contextualizava buscando o máximo de informação sobre o sujeito. Nesse ponto, os fotógrafos da Nova Objetividade tiveram maior êxito: enquanto a exploração da forma pela forma conseguiu em boa medida neutralizar qualquer outro sentido que não fosse o do objeto representado, Sander, por sua vez, não conseguiu eliminar a expressividade de seus personagens. A exatidão de seus retratos pode ser lida do ponto de vista dos vestígios materiais, mas não dos rastros deixados pelas 


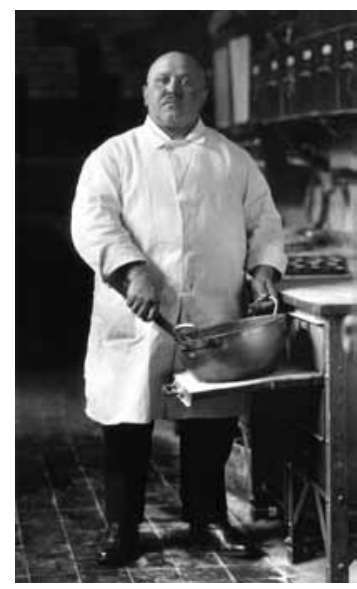

Figura 5

August Sander, O padeiro, 1928 expressões faciais. Assim, a figura do fotógrafo no quadro de Seiwert - desprovida de qualquer marca que o identifique, e anônima na aparência, pois não tem roupa, rosto ou expressividade - se aproxima mais das fotografias da Nova Objetividade do que das de Sander.

O retrato $O$ padeiro [figura 05], 1928, de Sander, é bem representativo sobre o que está sendo discutido. Em minha opinião, esse retrato está entre os que mais se aproximam do conceito de fotografia exata. $\mathrm{O}$ ambiente está posto claramente: o forno, o fogão, a chaminé ao fundo - aqui, a fala de Sander sobre não haver sombra que não se ilumine em fotografia cai muito bem; há um mínimo de detalhe que permite identificar o que está na escuridão - e o chão sujo de farinha caracterizam bem o espaço de trabalho de uma padaria. A categoria sócioprofissional também é clara: o personagem está caracterizado com um guarda-pó branco, com instrumentos de trabalho típicos de um padeiro, e posa como se estivesse misturando algo num tacho de metal. É uma imagem que dá pouco espaço ao estereótipo, e se enquadra bem no que Sander considera um típico padeiro.

A estrutura formal da fotografia contribui para a descrição, e a luz ambiente delineia claramente o corpo gordo e aparentemente forte do padeiro. A origem lateral da iluminação destaca a mão envolvida na ação de misturar os fornos e fogões da padaria. O ponto de vista frontal do fotógrafo estrutura formalmente o quadro fotográfico; ele determina o recorte da cena e destaca a altivez do personagem, estampando uma aparente equivalência na relação fotógrafo e fotografado. A frontalidade dá mais força ao rosto erguido e voltado para a luz, enfatizando o queixo e o nariz empinados. O peito estufado contrasta com o corpo estático, simulando a ação de se estar fazendo pão. O retratado parece estar se impondo ao fotógrafo; há um self em jogo, e isso não se descreve com precisão. É desse modo que a fotografia de Sander se distancia da arte exata.

\section{HSXX: uma encomenda virtual}

Os Progressistas de Colônia entendiam que a objetividade da fotografia não poderia se limitar à mera reprodução de suas obras. Em um texto sobre ADZ, publicado na revista $a$ bi z em 1930, Seiwert propunha que o caráter realista do projeto documental de August Sander tinha libertado o pintor para perseguir seu objetivo em pintar mais que sua representação mimética (ROTH, 2008). 
A missão que Sander imputou à fotografia e a ele próprio dá à fotografia um sentido que esteve, por assim dizer, solto na rua e que por esta razão não valia a pena até aqui recolher. A fotografia desencarrega a pintura da obrigação de produzir imagens da realidade da época que as gerações futuras reterão como documentos de nosso tempo, e isto acontecendo, ela reenvia a pintura à outra tarefa das artes da representação que é de mostrar o mundo, a partir da época na qual vivemos, numa perspectiva utópica (apud LANGE; HEITING, 1999, p.172, grifos nossos).

A fala de Seiwert revela uma encomenda virtual dos Progressistas de Colônia à fotografia - em especial a de Sander -, em que pesa o papel de libertadora da arte progressista e engajada. Essa expectativa, que se nutre do fato de a fotografia documental atuar sobre a realidade atual, revela uma visão profética do papel social da arte e da fotografia. Sua pintura poderia abrir mão da abordagem da realidade momentânea, como faziam George Grosz e Otto Dix, em favor de uma abordagem utópica do mundo de ideais anarquistas de sociedade, enquanto a fotografia documental, em especial a de Sander, se incumbiria de reportar a realidade tal qual ela é.

Sander, de sua parte, acredita no caráter profético da fotografia. Em um de seus escritos, no qual explicava a origem de HSXX, ele propôs que a fotografia deveria trazer consigo tarefas distintas das da pintura:

Nada me pareceu mais apropriado que dar, pela fotografia e com a fidelidade absoluta à natureza, um quadro de nosso tempo.

Os dias passados de todas as épocas nos deixaram escritos e livros ilustrados, mas a fotografia nos deu possibilidades e tarefas outras que a pintura. Ela pode trazer às coisas a beleza mais grandiosa, mas pode também trazer a verdade mais cruel; ela pode igualmente enganar de maneira extraordinária. Ver a verdade, tal como deveria ser nosso engajamento, mas nós devemos antes de tudo transmiti-la a nossos contemporâneos e à posteridade, quer ela nos seja favorável ou não.

Se eu, com pleno conhecimento de causa, tive o cuidado de ver as coisas tais como elas são e não como elas deveriam ou poderiam ser, eu quero que me perdoem, mas eu não posso fazer de outra forma (apud SANDER, G., 1995, p.21, grifos nossos). 
Tarefa e verdade: duas atribuições das quais a fotografia documental sempre teve dificuldade de escapar, até porque o enfoque sobre a realidade social foi sempre relacionado a um compromisso militante - não necessariamente de engajamento político - com a verdade. Mas isso não é de fato um problema, a não ser quando a fotografia é posta como substituto da realidade. Na fala de Sander, fica explícito seu entendimento a esse respeito; por outro lado, "ver as coisas tais como elas são e não como elas deveriam ou poderiam ser" deixa subentendido uma suposta verdade fotográfica.

O modo como August Sander competentemente organizou seu trabalho se revela na força com que ele conseguiu impor um modo de leitura. Suas proposições de que seu trabalho é um retrato real da realidade são justificadas no arrojado critério classificatório elaborado em prol do objetivo de apresentar um retrato da estrutura social alemã. A tipologia visual que norteia HSXX e o caráter realista que lhe cabe foi eficiente, ao ponto de artistas e intelectuais de sua época (Seiwert, Kurt Wolff, Walter Benjamin, Alfred Döblin), e de épocas posteriores (Susan Sontag), comprarem seu discurso. E isso não é sem justificativa: a Alemanha estava vivendo uma era extrema de grandes conturbações, e o caráter realístico de HSXX foi tomado como um retrato fiel daquele momento, e também como um documento para a posteridade, uma vez que a fotografia seria uma língua universal capaz de dialogar com toda a humanidade em qualquer época:

Pode-se através do exercício da visão, da observação e do pensamento, com a ajuda de uma câmera fotográfica e com a junção de uma data, capturar a história universal; e o potencial expressivo da fotografia [...] como língua universal permite exercer uma influência sobre a humanidade inteira (SANDER apud LANGE; HEITING, 1999, p.169, tradução e grifos nossos).

Essa citação conforma as aspirações de Sander com as dos Progressistas de Colônia de imprimir uma linguagem universal em suas obras. Nas obras dos Progressistas, tal universalização se concretiza na representação de figuras limpas e fáceis de serem identificadas: por exemplo, Burgueses e desempregados, 1922, de Seiwert, é uma tentativa clara de representar tipos sociais contrastantes num bom discurso marxista. Gerd Arntz, porém, foi o que mais se aproximou desse objetivo, com a criação dos isotipos que foram assimilados por vários de seus correligionários, dentre os quais, Peter Alma e o pró- 
prio Seiwert. As obras de Arntz foram provavelmente as que mais pesaram na construção tipológica de Sander; seus desenhos de Doze casas de uma época mostram tipos sociais genéricos sem rostos e limpos de expressão, ao contrário do que acontece no quadro de Seiwert.

Que a linguagem direta da fotografia documental possa universalmente ser compreendida, porque estabelece uma conexão direta com os objetos da realidade, facilitando o acesso do espectador, é algo que faz sentido. Mesmo desconhecendo o contexto no qual a produção fotográfica foi realizada, um observador atento poderá perfeitamente compreender o visível da imagem e do conjunto do trabalho, mas terá dificuldade para decifrar o que está subjacente. No entanto, atribuir à fotografia documental a capacidade de exercer uma influência sobre a humanidade nada mais é do que outra visão profética do papel da fotografia - essa missão universalista

Reprodutibilidade, ponto de vista e objetividade são, assim, três elementos-chave para compreender a intenção manifesta no quadro Mural para um fotógrafo, em que está subjacente o princípio dos Progressistas de Colônia de mostrar não os fatos da realidade cotidiana, mas os fundamentos culturais que estruturam a organização social dentro de uma realidade específica. Seiwert dizia que a Nova Objetividade estava preocupada em denunciar as discrepâncias da sociedade capitalista em nome da luta de classes, enquanto que os artistas progressistas estavam voltados para esclarecer as condições culturais nas quais a luta de classes iria ser travada. No que diz respeito ao trabalho, por exemplo, para Seiwert, o Estado comunista, tal qual se configurava na URSS e tal qual postulava o KPD, estava apenas incorporando a atual forma de exploração capitalista do trabalho e do trabalhador num novo regime, ao invés promover de fato uma revolução cultural que libertasse o trabalhador da cultura de exploração do trabalho na qual ele estava imerso e alienado de sua verdadeira condição. Assim como a máquina e todo o sistema produtivo capitalista alienava o trabalhador em prol do lucro, a máquina e o sistema produtivo burguês absorvido pelo Estado comunista alienavam o trabalhador em nome de um Estado autoritário.

Isso fica claro no vitral $O$ mundo do trabalho [figura o6], de 1932 - destruído em 1935 -, painel onde Seiwert reúne cenas de vários quadros seus. Nesse vitral, aparecem cenas representando várias formas de trabalho no campo e na cidade dentro do sistema capitalista, e cenas onde a cultura de exploração do trabalho é assimilada pela classe trabalhadora em seu 
cotidiano. Três quadros desse painel ilustram bem o que está sendo dito aqui. Um deles mostra operários posicionados em seqüência na linha de produção de uma fábrica; as cabeças dos trabalhadores aparecem ligadas ao sistema de roldanas, representando o homem como extensão da máquina. Outro, originalmente intitulado Massas, 1931, mostra uma série de pessoas enfileiradas no cotidiano fora da fábrica, representando a alienação do trabalhador na vida diária. O terceiro quadro, inspirado na obra original Mãe proletária, 1931, apresenta uma família operária em que o marido, a esposa e a criança no colo da mãe são representados num ambiente que lembra o quintal de uma casa, tendo ao fundo a chaminé de uma fábrica: o lugar da residência está condicionado pelo local de trabalho, e a vida cotidiana está condicionada ao cotidiano da fábrica.

Assim, Mural para um fotógrafo procura mostrar o sentido do trabalho, e não sua exploração; o fotógrafo dominando o

Figura 6 Franz Wilhelm Seiwert, O mundo do trabalho, 1932, aquarela preparatória para o vitral do Kunstgewerbemuseum Köln (Museu de Artes Aplicadas de Colônia), de $40 x 60 \mathrm{~cm}$ olhar objetivo da objetiva, e não o contrário, como acontece no interior da fábrica onde as frias roldanas - objetivas, no sentido de serem desprovidas de consciência - se mesclam com as cabeças mecanizadas e submetidas à fria objetividade do sistema produtivo capitalista.

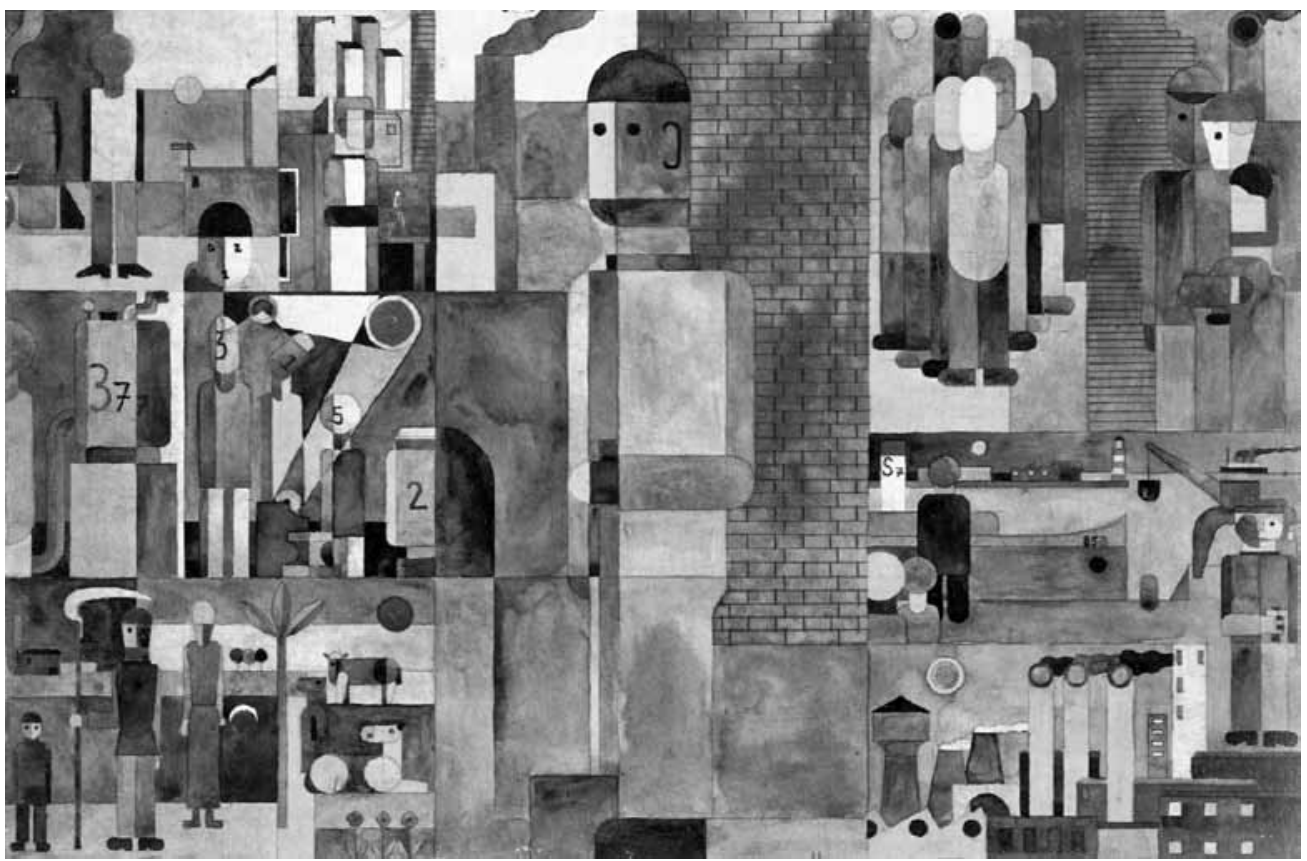


Eis, portanto, o papel utópico da arte dos Progressistas de Colônia: representar a cultura que estrutura a sociedade capitalista, a fim de despertar a consciência do trabalhador para sua verdadeira condição, sendo este o caminho para revolucionar de fato as relações sociais, libertando o homem de qualquer condição de submissão. À fotografia, cabe o papel de mostrar realisticamente a realidade tal qual ela é.

\section{Referências Bibliográficas}

ARGAN, Giulio Carlo. Arte Moderna: do Iluminismo aos movimentos contemporâneos. São Paulo: Cia. das Letras, 2006.

BASTIDE, Roger. Arte e sociedade. $3^{\mathrm{a}}$ ed. São Paulo: Nacional, 1979.

BAXANDALL, Michael. Padrões de intenção: a explicação histórica dos quadros. São Paulo: Companhia das Letras, 2006.

BENJAMIN, Walter. A obra de arte na era de sua reprodutibilidade técnica. In: Magia e técnica, arte e política: ensaios sobre literatura e história da cultura. Obras escolhidas, vol.1, $7^{\underline{a}}$ ed., $10^{\underline{a}}$ reimpressão. São Paulo: Brasiliense, 1994 ( $1^{\underline{a}}$ ed. 1985).

BOURDIEU, Pierre. As regras da arte: gênese e estrutura do campo literário. $2^{\mathrm{a}}$ ed. São Paulo: Companhia. das Letras, 2005.

DAVID, Batchelor; FER, Briony; WOOD, Paul. Realismo, racionalismo, surrealismo. A arte no entreguerras. Série Arte Moderna, práticas e debates. São Paulo: Cosac \& Naify, 1998. EVERETT, Martyn. Art As A Weapon: Frans Seiwert \& the Cologne Progressives. The Raven, n. 12, out./dez., 1990. Disponível em: <http://martyn.everett.googlepages.com/ artasaweapon>. Acesso em: 4 mar. 2009.

LANGE, Susanne. Introduction. In LANGE, Susanne; CONRATH-SCHOLL, Gabriele (orgs.). August Sander: Hommes du XX' siècle. Analyse de l' oeuvre. Paris : La Martinière, 2002.

; CONRATH-SCHOLL, Gabriele. August Sander: Hommes du XXe siècle - un concept en évolution. In: LANGE, Susanne; CONRATH-SCHOLL, Gabriele (orgs.). August Sander: Hommes du XX $\mathrm{X}^{\mathrm{e}}$ siècle. Analyse de l' oeuvre. Paris: La Martinière, 2002.

; HEITING, Manfred (ed.). August Sander, 1876-1964. Köln, Madrid, London, New York, Paris, Tokyo: Taschen, 1999. 
LUGON, Olivier. La photographie en Allemagne: anthologie de textes (1919-1939). Col. Rayon Photo. Nîmes, França: Jacqueline Chambon, 1997. . Le style docummentaire: d'August Sander à Walker Evans, 1920-1945. Col. Le Champ de l' Image. Paris: Éditions Macula, 2001.

MARESCA, Sylvain. La photographie: un miroir des sciences sociales. Col. Logiques sociales. Paris: L' Harmattan, 1996.

MATTICK JR., Paul. Modernisme et communisme antibolchévique: les Progressistes de Cologne. Oiseau Tempête, n. 4. Paris: 1988. Disponível em <http://abirato.free.fr/3oiseau/o4/ OISEAU4.HTM> Acessado em: 10 out. 2003.

MICHALSKI, Sergiusz. New Objectivity: Painting in Germany in the 1920s. Colônia, Alemanha: Taschen, 2003.

RICHARD, Lionel. A República de Weimar (1919-1933). Coleção vida cotidiana. São Paulo: Companhia das Letras / Círculo do livro, 1988.

ROSSI, Paulo José. August Sander e Homens do século XX: a realidade construída. 2010. 170 f. Dissertação (Mestrado em Sociologia) - Faculdade de Filosofia, Letras e Ciências Humanas da Universidade de São Paulo, São Paulo.

ROTH, Lynette. Painting as a weapon: Progressive Cologne 1920-33: Seiwert - Hoerle - Arntz. Colonia, Alemanha: Buchhandlung, 2008.

SANDER, August. Hommes du XXe siècle. 7 vol. Paris: La Martinière, 2002. (Edição trilíngue: francês, inglês e alemão.) . Antlitz der Zeit. Berlin: Schimer/Mosel, 2003.

SANDER, Gerd (org.). August Sander: Em photographie, il n' existe pás d' ombres que l' on NE puísse éclairer!". Paris: Centre National de La Photographie, 1995. WEBER, Max. Os fundamentos racionais e sociológicos da música. São Paulo: Edusp, 1995. (5 $5^{\mathrm{a}}$ edição. Rio de Janeiro: LTC, 2002.)

\section{NOTAS}

1. Não há uma unanimidade sobre a posição da Nova Objetividade em relação ao Expressionismo. Para Giulio Carlo Argan (2006), a Neue Sachlichkeit foi um movimento expressionista do pós-guerra, enquanto que, para Paul Wood (DAVID; FER; WOOD, 1998), trata-se de dois movimentos distintos estreitamente relacionados, como indicava a primeira exposição organizada por Gustav Hartlaub, intitulada Neue Sachlichkeit: pintores alemães desde o Expressionismo. Pelo fato de não ser este o foco de minha preocupação, assumi a posição de Argan como ponto de partida, uma vez que minha intenção é situar a arte engajada dos Progressistas de Colônia em relação à arte igualmente engajada de dois dos principais membros da Nova Objetividade: George Grosz e Otto Dix. 
2. Fragmento de um artigo de Otto Freundlich publicado em 1928 na revista a bis z.

3. Baxandall alerta para a "questão da instantaneidade fictícia de muitos quadros” (2006, p.85). A realização de uma obra geralmente não é instantânea, mas pode demorar dias, meses, ou mesmo anos para se concretizar; "ela resulta de uma relação intelectual e perceptual contínua entre [o autor] e o objeto da representação". Podemos igualmente transpor essa proposição para o observador. A compreensão da intenção de uma obra nem sempre acontece imediatamente. Muitas vezes, é preciso uma observação demorada numa relação "intelectual e perceptual" entre o observador e o objeto de apreciação, a obra. Sobre isso, Baxandall diz que a descrição de um quadro não tem como reproduzir o ato de observá-lo diretamente, "pois há óbvia incompatibilidade formal entre o ritmo com que percorremos o quadro com o olhar e o ritmo com que organizamos palavras e conceitos" (2006, p.34).

4. Muitas das pinturas dos diversos Progressistas de Colônia se perderam ou foram destruídas pelo nazismo. A documentação fotográfica dessas obras é a única referência visual que ainda se tem delas, sendo que parte significativa das reproduções foi feita por August Sander (ROTH, 2008, p. 29).

5. Freikorps: corpo de voluntários de extrema direita antibolchevique, convocado pelo Estado republicano para combater os rebelados contra o governo social-democrata.

6. Como desdobramento desse trabalho, Gerd Arntz criou uma extensa série de isotipos, configurando quase que um alfabeto visual universal. Tais pictogramas são explorados ou tomados como referência até os dias de hoje.

7. O termo realismo absoluto foi empregado por Hugo Sieker no artigo "Realismo absoluto: a propósito das fotografias de Albert Renger-Patzsch", publicado no periódico Der Kreis em 1928 (apud LUGON, 1997, p. 139).

8. No artigo "Uma concepção fotográfica do mundo", publicado no periódico Halle, 1929, Wolfgang Born tratou da fotografia e da percepção do olho contemporâneo numa geração de engenheiros marcada pela racionalidade da ciência, pela objetividade.

9. Podemos pensar a racionalidade fotográfica de maneira semelhante à que Max Weber (1995) pensou a racionalidade da música ocidental. É possível explicá-la a partir do estudo de seu desenvolvimento material técnicocientífico dentro de um quadro de necessidades sociais que variaram conforme o tempo histórico.

Recebido em: 04/04/2011

Aceito em: 18/05/2011

\section{PAULO JOSÉ ROSSI}

pjrossi@uol.com.br

Formado em Sociologia e Política pela Escola de Sociologia e Política de São Paulo. É mestre em Sociologia pela da Universidade de São Paulo cuja dissertação é voltada para o estudo da fotografia: August Sander e Homens do século XX: a realidade construída. 